\title{
USAGE AND KNOWLEDGE OF THE OVER-THE-COUNTER MEDICINES AMONG PATIENT VISITING OPHTHALMIC HOSPITAL IN WAD MEDANI, SUDAN
}

\author{
AMANI M ELSAYED* \\ Department of Pharmaceutics and Pharmaceutical Technology, College of Pharmacy, Taif University, Taif, Saudi Arabia. \\ E-mail: amanimoselsayed2015@gmail.com
}

Received: 07 January 2019, Revised and Accepted: 26 March 2019

\begin{abstract}
Objective: The aim of this work was to determine the usage pattern and knowledge of over-the-counter (OTC) medicines among Sudanese attending ophthalmic hospital in Wad Medani/Sudan.

Methods: It is a cross-sectional study in which 500 patients were surveyed.

Results: Participants had taken OTC medicines to treat headache, pain, allergy, heart pain, etc. General knowledge of participants was poor. Majority of respondents admitted having no knowledge about the active ingredient, the maximum dose, or side effects of paracetamol. One-third of respondents had taken a dose lower or higher than the recommended one. The main reason of taking larger dose was the intensive pain. More than a half (59.0\%) of respondent reported using more than one OTC medications when they had multiple symptoms. The results showed that knowledge was associated with the level of education. Regarding the sources of information, two-third of respondents (68.8) get information about the non-prescription medicine from the pharmacist. Only $10.4 \%$ read information about the OTC medicines from the leaflet in the package.
\end{abstract}

Conclusions: In Sudan, pharmacists play a major role in OTC medication safety as the illiteracy comprises high percentage.

Keywords: Over the counter, Medicines, Knowledge, Non-prescription.

(C) 2019 The Authors. Published by Innovare Academic Sciences Pvt Ltd. This is an open access article under the CC BY license (http://creativecommons. org/licenses/by/4. 0/) DOI: http://dx.doi.org/10.22159/ajpcr.2019.v12i5.33179

\section{INTRODUCTION}

Over-the-counter (OTC) drugs are medicines that are available without prescription to help individual to self-manage minor ailments. Consumers think that OTC medicines are safe since they are dispensed by pharmacists without a prescription from a registered medical practitioner. However, OTC has adverse effects and could be misused, abused, or interact with prescription drugs. The safe use of these products must be assessed by the patient without practitioner's intervention. Therefore, people must acquire knowledge about the safety of OTC medicines. Failure to comply with directions may lead to serious side effect (i.e., the correct dose, correct schedule, and for the intended disease). For example, overdose of acetaminophen has been associated with liver damage [1]. Analgesics increase the gastrointestinal tract bleeding even when taken at appropriate doses [2]. Cough products such as dextromethorphan and diphenhydramine may be abused due to their euphoric and alcohol-like effects [3].

OTC medications were used all around the world in developed and nondeveloped countries, among youth and adults, between people suffer from chronic diseases and those who have not these ailments [4-9].

Several studies had been done to assess the knowledge about OTC medications among different community categories. Sharma et al. evaluated the knowledge of residents of Chapapani-12, Pokhara in Nepal [10]. It was found that more than half of the respondents (54\%) had good knowledge. However, they were lacking the concept of safe usage of OTC drugs. Studies conducted in Saudi Arabia indicated that $58.1 \%$ of participants did not know the side effects of analgesics and most people lack knowledge about the appropriate dose of them [11,12]. A work done by the Academic Pediatrics in the USA to evaluate and compare knowledge and literacy of OTC medications among middle and high students illustrated that only $8 \%$ of the students responded correctly to side effects questions compared to $67 \%$ did not know [13]. Another study conducted in the USA by Kelly et al. demonstrated that teenagers lack baseline knowledge [14]. The average overall knowledge score of adolescence residing in New York (USA) was 44\% [15]. In Italy, 80\% of teenagers had an adequate information about OTC medicines [16]. Poor knowledge also makes people spend money on unnecessary medicines. For example, people thought that taking one pill of multivitamins daily may reduce the rate of incidence of chronic disease such as diabetes, ischemic heart disease, or stroke [17]. It was found that multivitamins have no role in preventing chronic disease and may be dangerous to health [17-19].

In many developed countries, campaigns were launched after national surveys about OTC medications to promote their safety usage. In Sudan, little information was found about the pattern of usage and knowledge of these medications, to the best of our knowledge. This study was carried out to identify the usage rate of OTC medicines among urban and rural patients visiting the ophthalmic hospital in Wad Medani, Sudan, and to describe the current knowledge and understanding about the range of the most common used OTC medicines, their side effects, and how they deal with toxicity problems. A questionnaire was designed, and the participants were surveyed by an expert pharmacist, so after respondent's answers, the pharmacists council them and clarifying wrong perceptions.

\section{METHODS}

The study is a community-based, cross-sectional survey. A questionnaire was developed after review of literature; then, it was modified and translated to Arabic [20]. The questionnaire consisted of seven parts. Part 1 for demographic information, other parts were: general health, usage of OTC medicines, general knowledge, sources of information, taking more dose, and side effects. The survey was modified after a pilot study on 30 individuals. 500 respondents age more than 18 years old were selected randomly and interviewed. Data were collected over 3 months from 
August 2018 to October 2018. The data were analyzed with the aid of SPSS (version 21). Chi-square and Fisher's exact tests were used to compare the results, whereas descriptive statistics describe the frequencies. Statistical significance was set at $\mathrm{p} \leq 0.05$. Ethical approval of the study was obtained from the Ministry of Health, Gezira State, Wad Medani, Sudan.

\section{RESULTS}

The current work shows that $47.2 \%$ of respondents were male and $52.8 \%$ were female. Nearly one-third of them aged between 30 and 49 years. Regarding educational status, illiterate and primary level education comprised high percentage, $23.3 \%$ and $19.7 \%$, respectively. Most respondents residing in rural areas (59.4\%) compared to $40.6 \%$ live in urban. The demographic data are depicted in Table 1.

About half of respondents had taken non-prescription medicines (53.2\%) in the past 6 months. $26.4 \%$ of these are vitamins followed by herbs (9\%). The respondents had taken non-prescription drugs to treat different ailments such as headache, relief of pain, allergy, and heart pain as illustrated in Fig. 1. Respondents who had taken OTC drugs to treat more than one ailment represent $(26.7 \%)$. Three-fifth $(59.7 \%)$ of respondents used paracetamol to relieve pain followed by diclofenac sodium tablets (Fig. 2). $24.3 \%$ of respondents used aluminum hydroxide/magnesium hydroxide products to relieve acidity, while $12.5 \%$ were taken ranitidine for the same purpose.

Two-third of respondents $(68.8 \%)$ get the information about the nonprescription medicine from the pharmacist. Only $10.4 \%$ read about the OTC medicines from the leaflet. Other sources such as media, another person represent low percentages (Fig. 3). The most important information that they asked or read about were direction for usage (28.8\%) followed by active ingredient (21\%) and other reasons as illustrated in Fig. 4.

About $63.5 \%$ of respondents did not know the active ingredient in the medication that they used for the treatment of their headache. Half of

Table 1: Sociodemographic characteristics of respondents $(n=500)$

\begin{tabular}{|c|c|c|}
\hline S. No. & Sample characteristics & Frequency (\%) \\
\hline \multirow[t]{3}{*}{1} & Gender & \\
\hline & Male & $233(47.2)$ \\
\hline & Female & $261(52.8)$ \\
\hline \multirow[t]{5}{*}{2} & Age & \\
\hline & $18-29$ & $120(24)$ \\
\hline & $30-49$ & $191(38.2)$ \\
\hline & $50-64$ & $163(32.6)$ \\
\hline & More than 65 & $26(5.2)$ \\
\hline \multirow[t]{7}{*}{3} & Education & \\
\hline & Illiterate & $116(23.2)$ \\
\hline & Primary level & $98(19.6)$ \\
\hline & Secondary level & $107(21.4)$ \\
\hline & Diploma & $31(6.2)$ \\
\hline & University level & $124(24.8)$ \\
\hline & Postgraduate & $22(4.4)$ \\
\hline \multirow[t]{5}{*}{4.} & Status & \\
\hline & Married & $274(55.6)$ \\
\hline & Single & $159(32.3)$ \\
\hline & Divorced & $41(8.3)$ \\
\hline & Widowed & $19(3.9)$ \\
\hline \multirow[t]{3}{*}{5.} & Living & \\
\hline & Urban & $274(59.4)$ \\
\hline & Rural & $187(40.6)$ \\
\hline \multirow[t]{8}{*}{6.} & Job & \\
\hline & Employed & $88(18.4)$ \\
\hline & Worker & $85(17.7)$ \\
\hline & Private business & 65 (13.6) \\
\hline & Housewife & $96(20)$ \\
\hline & Pensioner & $21(4.4)$ \\
\hline & Student & $69(14.4)$ \\
\hline & Idle & $55(11.5)$ \\
\hline
\end{tabular}

the respondents (53\%) did not know the maximum dose or side effects of paracetamol. Two-third of respondents (62.1\%) preferred to take ibuprofen and diclofenac sodium after food. Half of the respondents had no idea that the use of cough syrups for children below 2 years may lead to serious side effects. One-third of respondents had taken a dose higher or lower than the recommended dose. Those taken a higher dose comprised $18.8 \%$. About half (44.8\%) of them explained, the reasons of taking larger dose were the intensive pain. More than half $(59.0 \%)$ of respondent could take more than one OTC medications when they had multiple symptoms. Two-fifth (39.6) of respondents experienced side effects from OTC medications and one-fifth (20.5\%) of them consulted a doctor.

\section{DISCUSSION}

In the current work, about half of the participants used non-prescription medicines. In Northern Ireland, only one-third of the respondents had taken OTC medicines [21].

Vitamins are widely used among participants (26\%). Same prevalence rate was found in Saudi Arabia (22\%) [22]. In contrast, the prevalence rate in the US reached $50 \%$ among adults and they spend about $\$ 23$

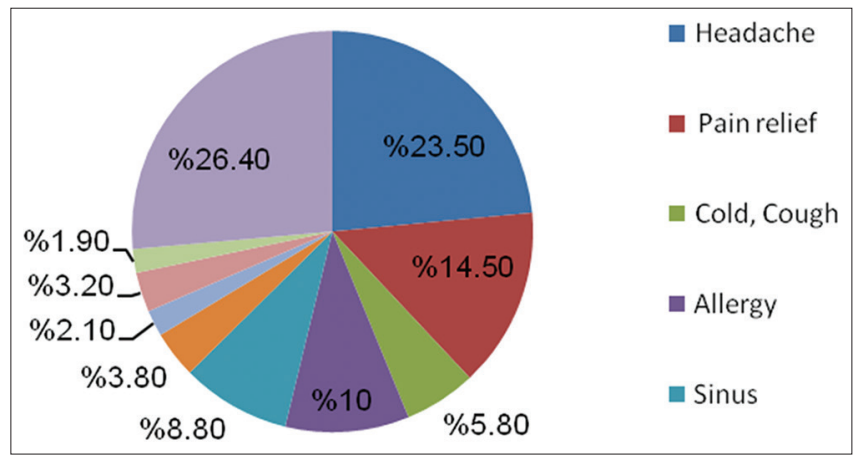

Fig. 1: Reasons for taking non-prescription medicines

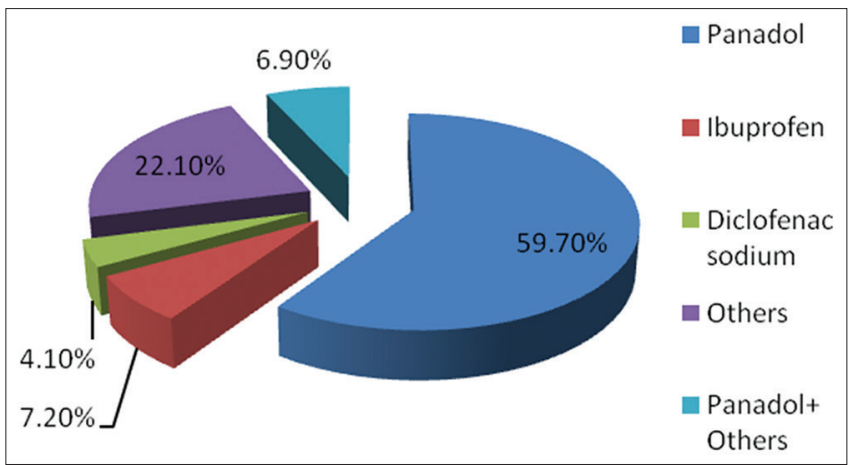

Fig. 2: Analgesics taken by respondents

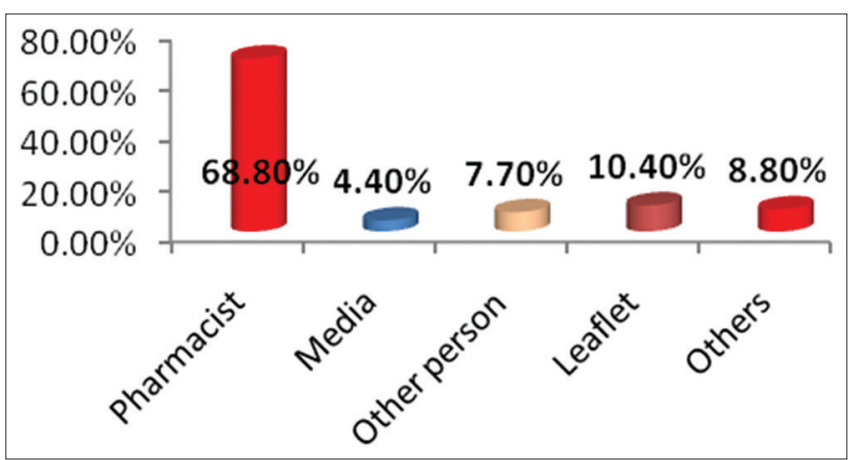

Fig. 3: Sources of information 


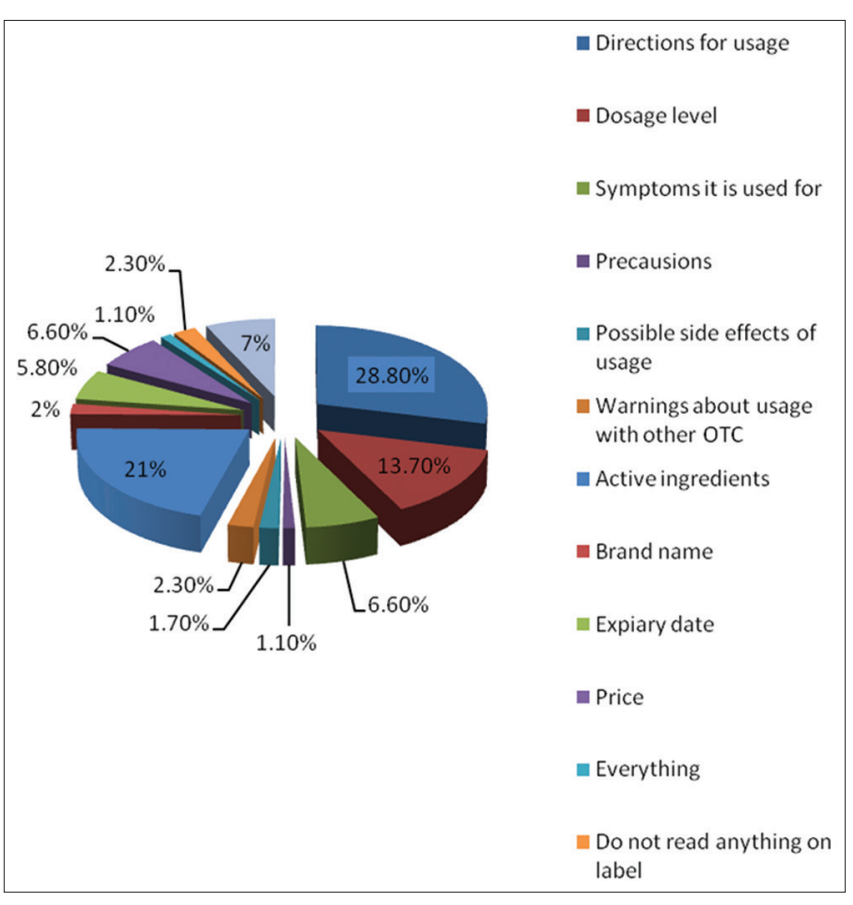

Fig. 4: Respondent's use of over-the-counter labels

billion annually because they believe that multivitamins could protect them from chronic diseases such as cancer, cardiovascular diseases, and Type 2 diabetes. Canadian expends about $\$ 356.6$ million on vitamins [6]. Vitamins were consumed by both adults and young aged population. Lieberman et al. found that $42 \%$ of the US college students surveyed used multivitamins/mineral to promote general health, provide more energy, and increase muscle strength or to enhance performance [23]. Same trend was observed among Malaysian college students where the prevalence of using multivitamins was 43\% [24]. Although the prevalence was high, many of them did not have accurate information about vitamins.

Nearly $9 \%$ of respondents had taken herbs during the past 6 months. Sudanese uses herbs to treat different ailments such as malaria, diabetes, microbial infections, rheumatic pain, wounds, and cancer [25]. A previous study stated that $90 \%$ of Sudanese depend on traditional medicines due to increase cost of health care, limited access to modern synthetic drugs, and high percentage of population are nomads [26]. The lower percentage (9\%) may be explained by the fact that the population in this report were settled and could access modern medicines easily.

The least often used drugs are weight loss products (3.3\%). Conventionally, weight gain is the common beauty practice in Sudan and women must accomplish a societal desirable body weight [27]. It seems that these beliefs are not changed yet.

Interview participants used OTC medicines mostly to treat headache (37.6\%). Higher rate may be due to higher malaria incidence in Sudan. About 9 million malaria episodes were registered in Sudan in 2002 [28]. Headache is the common symptoms of malaria. The most widely used analgesic was paracetamol (59.7\%) owed to its widespread availability and low price. However, one-half of the respondents (53\%) did not know the maximum dose or side effects of paracetamol. This may be due to illiteracy as $23.3 \%$ of participant was illiterate. Paracetamol is a safe medicine; however, it may result in hepatotoxicity if taken at doses above $4.0 \mathrm{~g} /$ day or below this in certain populations. Paracetamol accounts for about one-half of drug-related cause of acute liver failure in the USA, the UK, Canada, and most European countries [29]. In this work, one-fifth of participants were exposed to high dose of OTC medicines and about one-half of them had taken larger doses to relieve intensive pain because they were ignorant of the maximum dose and side effects.
Other analgesics such as diclofenac sodium and ibuprofen were used less frequently. These analgesics should be taken after food to decrease gastric upset. However, one-third of respondents had taken them before food. Analgesics are widely used in other countries. Study conducted in Belgium showed that $68.8 \%$ of sample used paracetamol and $46.8 \%$ used nonsteroidal anti-inflammatory drugs [30]. In Oman, the most frequent used medication was analgesics and antipyretic drugs [9]. Pharmacists are the major source of information about OTC medicines as evident by high rates of consumers consulting pharmacists (68.8\%). Only $10.4 \%$ of Sudanese participants claimed to read labels carefully. Same trend was observed among Pakistani university students who claimed that they had never read the leaflet information during their lifetime [31]. In contrast, $80 \%$ of Northern Ireland respondents reported that they are always or often reading the instructions on the OTC drug package before they used the product and $91 \%$ of Canadians claimed to read labels carefully before using a product for the $1^{\text {st }}$ time $[7,21]$. There was apparent lack of concern about warning of usage, possible side effects, or precautions as only very few participants asked about them. Respondents in Sudan may think that OTC medicines are safe, and there are no reasons to be worried about them as $36.1 \%$ of them had taken high doses when they suffered from intensive pain. Only $5 \%$ of Canadian was non-compliant to dose schedule [7].

In general, the knowledge of participants was poor. For example, two-third of respondents did not know the active ingredients in their favorite pain killer. The predominant factor that affects the level of the knowledge was the education. There was a significant difference between the different categories in response to the five knowledge questions $(p<0.05)$. Other sociodemographic variables such as sex, job, status, and living were not significant.

\section{CONCLUSIONS}

Results indicated high rate of usage of OTC medicines, poor knowledge, and lack of concern. This suggests that effective intervention method should be implemented to avoid harmful effects of these drugs.

\section{ACKNOWLEDGMENT}

The author would like to thank the pharmacist, Fatima Elsayed for her efforts in interviewing the patients.

\section{AUTHOR'S CONTRIBUTION}

The author designs the study, conducts the analysis, and writes the manuscript.

\section{CONFLICTS OF INTEREST}

The author declares no potential conflicts of interest.

\section{REFERENCES}

1. Jayadi T, Widiasmoko B. Curcumin benefits as antioxidant, anti inflamation and antiapoptosis ameliorate paracetamol toxicity. Asian J Pharm Clin Res 2018;11:1-3.

2. Dawane JK, Khade Y, Pandit V. Evaluation of use of analgesics in pain management among surgeons in a tertiary care hospital. Asian J Pharm Clin Res 2018;11:124-8.

3. Bryner SD, Ghamdi MM. Dextromethorphan abuse in adolescence: An increasing trend: 1999-2004. Arch Pediatr Adolesc Med 2006; 160:1217-22.

4. Shorog EM, Alburikan KA. The utilization of nonprescription medications in Saudi patients with cardiovascular diseases. Saudi Pharm J 2018;26:120-4.

5. Tawfic QA, Bellingham G. Postoperative pain management in patients with chronic kidney disease. J Anaesthesiol Clin Pharmacol 2015; 31:6-13.

6. Hashempur MH, Heydari M, Mosavat SH, Heydari ST, Shams M. Complementary and alternative medicine use in Iranian patients with diabetes mellitus. J Integr Med 2015;13:319-25.

7. Taylor J. Over-the-counter medicines and diabetes care. Can J Diabetes 2017;41:551-7. 
8. Albatti TH, Alawwad S, Aldueb R, Alhoqail R, Almutairi R. The self medication use among adolescents aged between 13-18 years old; prevalence and behavior, Riyadh Kingdom of Saudi Arabia, from 20142015. Int J Pediatr Adolesc Med 2017;4:19-25.

9. Abdo-Rabbo A, Al-Ansari M, Gunn BC, Suleiman BJ. The use of medicines in Oman: Public knowledge, attitudes and practices. Sultan Qaboos Univ Med J 2009;9:124-31.

10. Sharma D, Gurung D, Kafle R, Singh S. Knowledge and practice on over-the-counter drugs among adults of age group 20 and above residing in Chapapani-12, Pokhara, Kaski, Nepal. Int J Sci Rep 2017; 379:2454-6.

11. Babakor SD, Ghamdi MM. Prevalence and determinants of over-thecounter analgesics usage among patients attending primary health care centers in Jeddah, Saudi Arabia. J Young Pharm 2018;10:91-7.

12. Karami N, Altebainawi A, Alfarki S, Aldossari N, Asiri A, Aldahan M, et al. Knowledge and attitude of analgesics use among Saudi population: A cross-sectional study. Int J Med Sci Public Health 2018;7:137-42.

13. Stone JA, Lester CA, Aboneh EA, Phelan CH, Welch LL, Chui MA, et al. A preliminary examination of over-the-counter medication misuse rates in older adults. Res Social Adm Pharm 2017;13:187-92.

14. Kelly T, Conn KM, Zak M. Evaluation of over-the-counter medication knowledge and literacy in adolescent students. Acad Pediatr 2018; 18:556-62.

15. Wilson KM, Singh P, Blumkin AK, Dallas L, Klein JD. Knowledge gaps and misconceptions about over-the-counter analgesics among adolescents attending a hospital-based clinic. Acad Pediatr 2010; 10:228-32

16. Panero C, Persico L. Attitudes toward and use of over-the-counter medications among teenagers: Evidence from an Italian study. Int J Mol Sci 2016;8:65-71.

17. Huang HY, Caballero B, Chang S, Alberg AJ, Semba RD, Schneyer CR, et al. The efficacy and safety of multivitamin and mineral supplement use to prevent cancer and chronic disease in adults: A systematic review for a national institutes of health state-of-the-science conference. Ann Intern Med 2006;145:372-85.

18. Kamangar F, Emadi A. Vitamin and mineral supplements: Do we really need them? Int J Prev Med 2012;3:221-6.

19. Guallar E, Stranges S, Mulrow C, Appel LJ, Miller ER $3^{\text {rd }}$. Enough is enough: Stop wasting money on vitamin and mineral supplements. Ann
Intern Med 2013;159:850-1.

20. National Council on Patient Information and Education (NCPIE)/ Harris Interactive. Attitudes and Beliefs about the use of OTCs: A Dose of Reality; 2002. Available from: http://www.bemedwise.org/survey/ final_survey.pdf. [Last accessed on 2018 May 10].

21. Wazaify M, Shields E, Hughes CM, McElnay JC. Societal perspectives on over-the-counter (OTC) medicines. Fam Pract 2005;22:170-6.

22. Albakri I, Almalki I, Bukhari, Buhari M, Ekram S, Aldhubayi S. Prevalence of intake of dietary supplements in the population of Saudi Arabia Jeddah. Egypt J Hosp Med 2017;69:1570-5.

23. Lieberman HR, Marriott BP, Williams C, Judelson DA, Glickman EL, Geiselman PJ, et al. Patterns of dietary supplement use among college students. Clin Nutr 2015;34:976-85.

24. Al-Naggar RA, Chen R. Prevalence of vitamin-mineral supplements use and associated factors among young Malaysians. Asian Pac J Cancer Prev 2011;12:1023-9.

25. Karar MG, Kuhnert N. Herbal drugs from Sudan: Traditional uses and phytoconstituents. Pharmacogn Rev 2017;11:83-103.

26. Elegami AA, El-Nima EI, El Tohami MS, Muddathir AK. Antimicrobial activity of some species of the family Combretaceae. Phytother Res 2002;16:555-61.

27. Ahmed I, Saltus R. A thematic analysis of female university students perceptions of idealised body image in Sudan and their experiences of performing common beauty practices. Divers Equal Health Care 2015;12:40-7.

28. Abdalla SI, Malik EM, Ali KM. The burden of malaria in Sudan: Incidence, mortality and disability adjusted life years. Malar J 2007;6:97.

29. Clark R, Fisher JE, Sketris IS, Johnston GM. Population prevalence of high dose paracetamol in dispensed paracetamol/opioid prescription combinations: An observational study. BMC Clin Pharmacol 2012;12:11.

30. Mehuys E, Crombez G, Paemeleire K, Adriaens E, Van Hees T, Demarche S, et al. Self-medication with over-the-counter analgesics: A survey of patient characteristics and concerns about pain medication. J Pain 2018;18:1-9.

31. Tariq M, Din F. Poor knowledge of university students regarding paracetamol; a wakeup call for public healthcare practitioners. Cogent Med 2017;4:1-12. 